УдК: 635.621.3:631.811.98

06.00.00 Сельскохозяйственные науки

СРАВНИТЕЛЬНАЯ ОЦЕНКА РАЗЛИЧНЫХ СХЕМ ОРГАНИЗАЦИИ ГИБРИДНОГО СЕМЕНОВОДСТВА КАБАЧКА В УСЛОВИЯХ КРАСНОДАРСКОГО КРАЯ

Гиш Руслан Айдамирович

доктор сельскохозяйственных наук, профессор, зав. кафедрой овощеводства

Кубанский Государственный Аграрный Университета, Краснодар, Россия

Чайкин Константин Олегович научный сотрудник ООО «НИИ Овощеводства Защчищенного Грунта», $x$. Новоукраинский, Крымский район, Краснодарский край, Россия

e-mail: chaikin@gavrish.ru

В условиях Краснодарского края рассмотрены количественные и качественные характеристики семян, полученных при использовании различных схем организации гибридного семеноводства кабачка в условиях Краснодарского края. В результате изучения различных приемов в технологии получения гибридных семян кабачка, установили эффективность использования свободного опыления, а также проведена оценка апробационных признаков растений гибрида $\mathrm{F}_{1}$, полученных при различных схемах организации гибридного семеноводства кабачка

Ключевые слова: ГИБРИДНОЕ СЕМЕНОВОДСТВО, СВОБОДНОЕ ОПЫЛЕНИЕ, КАБАЧОК, ОБРАБОТКА, СЕМЕНА, ЭТРЕЛ (2-ХЭФК)

Doi: $10.21515 / 1990-4665-121-072$
UDC: $635.621 .3: 631.811 .98$

Agriculture

\section{COMPARATIVE EVALUATION OF DIFFERENT SCHEMES OF ORGANIZATION OF SQUASH HYBRID SEED PRODUCTION IN THE CONDITIONS OF THE KRASNODAR REGION}

Gish Ruslan Aydamirovich

Doctor of Agricultural sciences, professor, head of the Vegetable growing department Kuban State Agrarian University, Krasnodar, Russia

Chaykin Konstantin Olegovich scientific employee LTD «Research Institute of Vegetable Growing Greenhouse», Novoukrainsky, Krymsk district, Krasnodar region, Russia e-mail: chaikin@gavrish.ru

In the conditions of the Krasnodar region, we consider the quantitative and qualitative characteristics of seeds obtained when using different schemes of organization of hybrid seed production of squash in the Krasnodar region. As a result of studying various techniques in the production of hybrid seed of summer squash, we have established the effectiveness of using open pollination, and assessed the approbation of the signs of $F_{1}$ hybrid plants obtained under different schemes of organization of hybrid seed production of squash

Keywords: HYBRID SEED, SQUASH, FREE POLLINATION, PROCESSING, SEEDS, ETHREL (2 HEFK)

\title{
Введение.
}

В России выращивают, около, сорока видов овощных растений. Среди большого разнообразия возделываемых культур на территории РФ, нужно отметить кабачок как наиболее скороспелый представитель семейства Тыквенных (Cucurbitaceae). В своей биологической спелости плоды способны к длительному хранению, удовлетворяя потребности населения в витаминах, как в летний, так и в осенне-зимний период. Кроме 
того они являются сырьем для консервной промышленности (соки, пюре, икра и др.), в том числе и для детского питания [3].

По данным на 2006 год, в государственном реестре селекционных достижений зарегистрировано 23 сорта и 9 гибридов кабачка, отечественный производитель семян представлен четырьмя гибридами, зарубежные фирмы - пятью гибридами. Анализируя данные 2015 года, ситуация изменилась в лучшую сторону: зарегистрировано - 67 сортов и 68 гибридов, из которых на долю гибридов отечественной селекции приходится только третья часть.

В современном сельском хозяйстве высококачественный посевной материал как средство производства имеет первостепенное значение. Практическое использование гибрида в производстве, возможно лишь при эффективной организации его семеноводства, важной задачей которого является получение качественных семян с высоким уровнем гибридности.

К сожалению, отечественные гибриды кабачка, недостаточно широко распространены в производстве из-за сложностей процесса получения гибридных семян и отсутствия научно-обоснованных сортовых технологий их семеноводства в промышленных масштабах. Поэтому разработка элементов технологии получения качественных гибридных семян, обеспечивающих их высокую гибридность, минимизирующих затраты труда, учитывающих особенности природно-климатических условий зоны ведения семеноводства, в настоящее время является актуальной задачей современных исследований.

\section{Объекты и методы исследований.}

Применение Этрела на растениях кабачка линии К69, в зависимости от варианта обработки, дает возможность, в большей или меньшей 
степени, увеличить период отсутствия мужских цветков на растении $[6,7,8,9,10,11,12]$.

Для оценки целесообразности использования дополнительных приемов в технологии получения гибридных семян, проведена серия исследований, основанных на организации разных схем гибридного семеноводства кабачка, отличающихся методическими подходами:

- свободное переопыление между родительскими линиями кабачка без дополнительных приемов (контроль);

- искусственное опыление пыльцой отцовского компонента с последующей их изоляцией и ручная кастрация материнских растений (эталон);

- естественное опыление между родительскими линиями с регулярной ручной кастрацией растений материнской формы;

- естественное опыление с использованием схемы обработки растений материнской линии препаратом Этрел (трехкратное опрыскивание в фазы 3+4+5 настоящих листьев, доза 350 мг/л д.в.) [6,7].

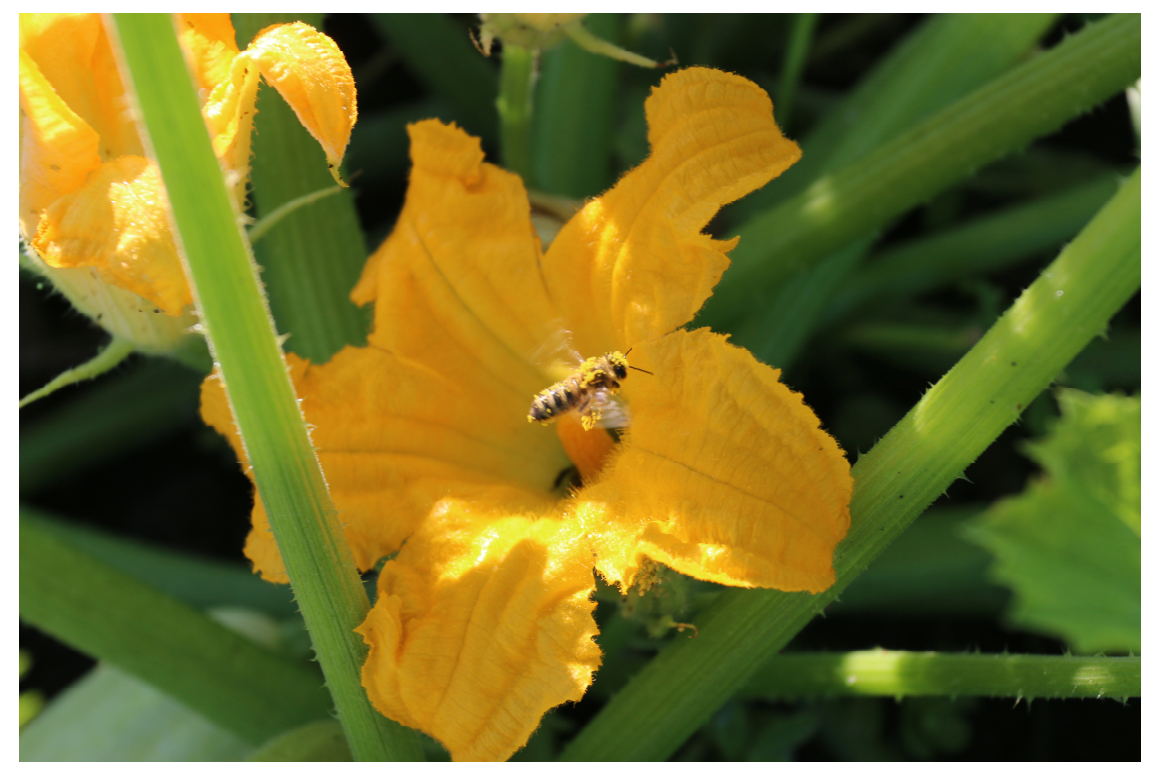

Рисунок 1 - Естественное опыление насекомыми (Краснодарский край, 2014 г.) 
Исследования проводили в 2 этапа:

1. Изучение основных качественных и количественных характеристик полученных семян;

2. Оценка апробационных признаков растений гибрида $F_{1}$, полученных при различных схемах организации гибридного семеноводства кабачка.

Материалом исследований послужили родительские линии (К-69 и К-31) перспективного гибрида кабачка селекции фирмы «Гавриш», семена гибрида F1 831/14 на основе комбинации К-69×К-31; регулятор роста с коммерческим названием Этрел (65 \% в.р.).

Исследования организованы в предгорной зоне Краснодарского края, C использованием изолированных участков для каждой изучаемой схемы семеноводства и типа опыления (рис. 2).

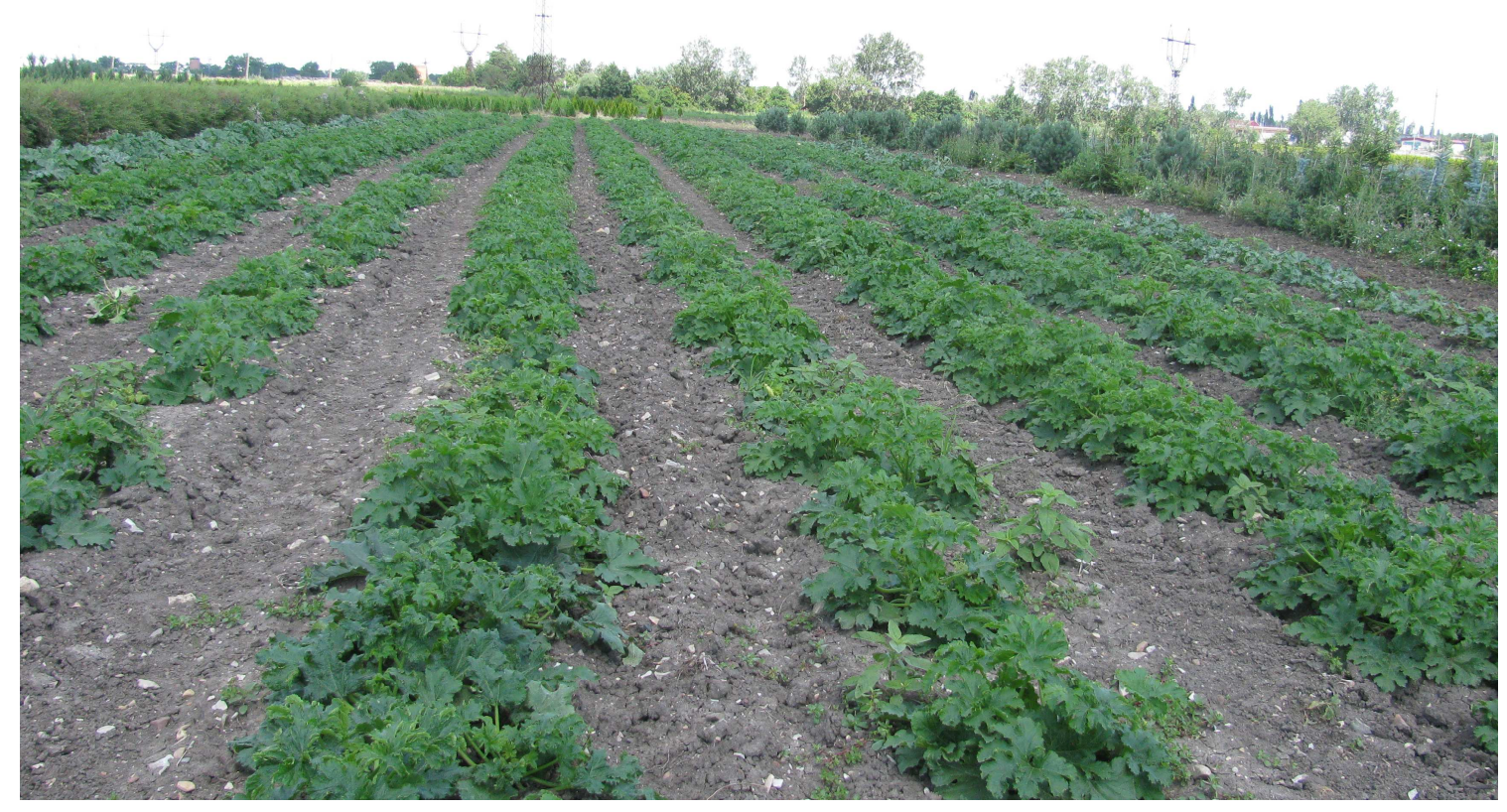

Рисунок 2 - Участок размножения гибрида кабачка $\mathrm{F}_{1}$ 831/14 (Краснодарский край, 2014 г.)

На участке сортоиспытания и грунтового контроля высевали по 100 семян гибрида F1, полученных при различной схеме организации 
семеноводства, в трехкратной повторности. Способ размещения систематический. Площадь опытной делянки 49 м2. Общая площадь - 750 $\mathbf{M}^{2}$.

Сбор семенных плодов (3 шт. - с растения) и выделение семян прово-дили ручным способом в первой и второй декаде сентября. Семенную про-дуктивность оценивали как теоретическую (потенциальную), так и фактиче-скую урожайность семян, в силу ряда причин (погодные условия года, агротехническое обеспечение, человеческий фактор и др.). Оценку семенной продуктивности растений и качества полученных семян проводили согласно ГОСТ Р52 171-2003 по следующим признакам: количество семян в семеннике, масса 1000 штук семян, энергия прорастания, всхожесть семян.

Также согласно ГОСТ Р52 171-2003 определяли гибридные качества полученных семян по наличию у растений $\mathrm{F}_{1}$ следующих маркерных морфологических признаков:

\section{Степень рассеченности листовой поверхности.}

Рассеченность листьев у растений кабачка уменьшает испарение влаги, ослабляет действие ветра. В зависимости от возраста растений степень рас-сеченности листа различна. Следует отметить, что нормальную рассечен-ность листовой пластины, присущую сорту, имеет 12 - 15-й лист [2,4]. Степень рассеченности листовой пластины является хорошим маркерным признаком: слабо рассеченный лист - до 1/3 площади листа; средне рассеченный - до 1/2 площади листа; сильно рассеченный более 1/2 площади листа рассечена. Тараканов Г.И., Теханович Г.А., Елацкова А.Г. (2001), установили промежуточный характер наследования этого признака по отношению к не рассеченному листу [5]. В своих опытах Долженко М.В. (2009), отметила, что рассеченность листа в большинстве случаев носит доминирующий характер наследования, иногда промежуточный [3]. 
Наличие аэренхимы на поверхности листовой пластины.

Аэренхима (сизо-зеленые участки листа) - воздухоносная ткань, состоящая из мертвых клеток и межклеточного пространства, заполненных воздухом, размещается на верхней стороне листа под эпидермисом. Наличие ткани позволяет растению частично отражать солнечные лучи в жаркое время и экономить воду на охлаждение. Наличие аэренхимы носит промежуточный характер наследования или доминирует, а также проявляется на ранних этапах роста растения, начиная с 4 - 5-го настоящего листа. Наличие аэренхимы оценивается по пяти балльной шкале: 0 - отсутствие признака; 1 - очень слабое, менее 10 \%; 2 - слабое, 11-30 \%; 3 - среднее, 31-50 \%; 4 - сильное, 51-70 \%; 5 - очень сильное, более 70 \% площади листовой пластины [1,2,3].

При проведении сортоиспытания полученных при разных схемах семеноводства гибридных растений F1 кабачка сбор и учет плодов в технической спелости проводили два раза в неделю. Собранные плоды с каждого варианта опыта взвешивали и относили к товарным или нетоварным. Товарную часть составляли: ровные, здоровые, без какихлибо повреждений плоды. К нетоварным относили, потерявшие товарный вид плоды: гнутые, треснувшие, поврежденные болезнями и вредителями. В товарной части фиксировали: длину, ширину и массу плода, среднюю массу плода. На основании полученных данных вычисляли общую и товарную урожайность.

\section{Обсуждение результатов первого этапа исследований.}

Анализируя полученные результаты, следует отметить отсутствие либо незначительное влияние препарата Этрел и типа опыления на биометрические параметры семенного плода, в отличие от завязываемости семян (табл. 1). 
Таблица 1 - Количественные характеристики семенных плодов кабачка и урожайность семян $F_{1}$ в зависимости от используемого типа опыления и схемы организации семеноводства (2012-2014 годы)

\begin{tabular}{|c|c|c|c|c|c|}
\hline \multirow[b]{3}{*}{ Признаки } & \multicolumn{4}{|c|}{ Тип и схема опыления } & \multirow[b]{3}{*}{$\mathrm{HCP}_{05}$} \\
\hline & \multirow{2}{*}{$\begin{array}{c}\text { Искусственное } \\
\text { с ручной } \\
\text { кастрацией и } \\
\text { изоляцией } ๆ \\
\text { цветков } \\
\text { (эталон) }\end{array}$} & \multicolumn{3}{|c|}{$\begin{array}{c}\text { Естественное (свободное) } \\
\text { без изоляции } 9 \text { цветков } \\
\end{array}$} & \\
\hline & & $\begin{array}{c}\text { без кастрации } \\
\text { и обработок } \\
\text { (контроль) }\end{array}$ & $\begin{array}{c}\text { с ручной } \\
\text { кастрацией } \\
\hat{\jmath} \text { цветков }\end{array}$ & $\begin{array}{c}\text { трехкратная } \\
\text { обработка } \\
\text { Этрелом } \\
\text { без } \\
\text { кастрации }\end{array}$ & \\
\hline $\begin{array}{l}\text { Длина } \\
\text { семенника, см }\end{array}$ & 40,6 & 40,0 & 39,6 & 40,1 & 0,6 \\
\hline $\begin{array}{l}\text { Диаметр } \\
\text { семенника, см }\end{array}$ & 17,0 & 16,7 & 16,4 & 16,3 & 0,5 \\
\hline $\begin{array}{l}\text { Масса } \\
\text { семенника, г }\end{array}$ & 1700 & 1700 & 1720 & 1680 & 38,5 \\
\hline $\begin{array}{l}\text { Масса семян в } \\
\text { семенном плоде, г }\end{array}$ & 20,0 & 22,1 & 22,4 & 23,3 & 2,1 \\
\hline $\begin{array}{l}\text { Масса семян с } \\
\text { растения, } Г\end{array}$ & 60,1 & 66,3 & 67,2 & 69,9 & 6,1 \\
\hline $\begin{array}{l}\text { Количество семян } \\
\text { с растения, шт. }\end{array}$ & 550 & 576 & 578 & 584 & 21,9 \\
\hline $\begin{array}{l}\text { Теоритический } \\
\text { выход семян, кг/га }\end{array}$ & 720 & 796 & 806 & 839 & 73,3 \\
\hline $\begin{array}{l}\text { Фактический } \\
\text { выход семян, кг/га }\end{array}$ & 600 & 660 & 670 & 690 & 56,4 \\
\hline
\end{tabular}

Свободное опыление эффективнее по сравнению с искусственным опылением, в результате средняя масса семян в семенных плодах увеличилась в среднем на 10-17\%. При этом продуктивность семенного плода материнских растений, обработанных Этрелом, в среднем было на $5 \%$ выше, относительно контроля (свободное переопыление), что в 
конечном итоге привело к общему увеличению количества полученных семян $\mathrm{F}_{1}$

Средняя прибавка фактической урожайности гибридных семян с трех плодов, в данном варианте, составила 30 кг/га относительно контроля и 20 кг/га, по сравнению со схемой семеноводства, основанной на естественном опылении с ручной кастрацией (табл.1). Следует отметить, что фактическая урожайность семян, как конечный результат гибридного семеноводства кабачка, в силу ряда причин (погодные условия года, агротехническое обеспечение, человеческий фактор и др.) в среднем за годы исследований составила около $83 \%$ от теоретического (потенциального) выхода семян с 1 га.

Посевные качества полученных семян кабачка определяются энергией прорастания, всхожестью, массой 1000 семян, и являются основной характеристикой их пригодности к посеву. Наиболее положительные результаты по совокупности изучаемых характеристик получены в варианте с естественным опылением при использовании оптимальной схемы обработки Этрелом (табл.2). Вариант семеноводства с использованием искусственного опыления, имел наименьшее значение массы 1000 семян, но по другим характеристикам, находился на уровне, либо не существенно ниже остальных схем семеноводства с естественным опылением. 
Таблица 2 - Характеристика посевных качеств полученных семян кабачка $\mathrm{F}_{1}$, в зависимости от используемого типа опыления и схемы организации семеноводства (2012-2014 годы).

\begin{tabular}{|c|c|c|c|c|}
\hline Тип опыления & $\begin{array}{c}\text { Масса 1000 } \\
\text { семян, гр. }\end{array}$ & $\begin{array}{c}\text { Энергия } \\
\text { прорастания, } \\
\%\end{array}$ & $\begin{array}{c}\text { Лабораторная } \\
\text { всхожесть, } \\
\%\end{array}$ & $\begin{array}{c}\text { Полевая } \\
\text { всхожесть, } \\
\%\end{array}$ \\
\hline $\begin{array}{c}\text { Искусственное с } \\
\text { изоляцией и ручной } \\
\text { кастрацией (эталон) }\end{array}$ & 109,0 & 82,3 & 99,7 & 92,6 \\
\hline $\begin{array}{c}\text { Естественное без } \\
\text { кастрации и обработок } \\
\text { (контроль) }\end{array}$ & 115,9 & 83,2 & 99,4 & 93,5 \\
\hline $\begin{array}{c}\text { Естественное с } \\
\text { Ручной кастрацией }\end{array}$ & 116,3 & 83,0 & 99,2 & 93,1 \\
\hline $\begin{array}{c}\text { Естественное с } \\
\text { оптимальной схемой } \\
\text { обработки Этрелом }\end{array}$ & 119,4 & 84,6 & 99,4 & 93,5 \\
\hline НСР & 6,8 & 1,5 & 0,3 & 0,7 \\
\hline
\end{tabular}

Как следует из полученных данных, среди испытанных схем организации семеноводства на основе свободного опыления, метод сдерживания цветения мужских цветков с помощью Этрела, наряду с вариантом, где проводили регулярную ручную кастрацию материнских растений, имеет наиболее положительные результаты с точки зрения количества и качества полученных семян гибрида $\mathrm{F}_{1 .}$

\section{Обсуждение результатов второго этапа исследований.}

Известно, что допустимым уровнем гибридности растений для использования гибридов $\mathrm{F}_{1}$ кабачка в производстве, является 95\%. В результате проведенного грунтового контроля, с использование двух маркерных морфологических признаков, установили уровень гибридности полученных семян $F_{1}$ (табл. 3). Следует отметить, что оба маркерных признака сцеплены между собой (Дютин К.Е.,2000), что повышает достоверность оценки гибридного потомства. В нашем случае сильная рассеченность листовой пластины и наличие сильно выраженной 
аэренхимы (51-70\% от общей площади листа) присуще отцовской линии гибрида, а средняя рассеченность листа и отсутствие аэренхимы материнской линии. Листовая пластина гибрида, характеризуется как сильно рассеченной со средним наличием аэренхимы (31-50\% от общей площади листа).

Высокая результативность гибридизации, как и следовало ожидать, получена при использовании искусственного опыления (эталон) гибридность растений $\mathrm{F}_{1}$ в среднем составила 99,0\%. Соответственно самая низкая 65\% - в контроле при свободном опылении, без каких-либо дополнительных приемов, обеспечивающих отсутствие самоопыления материнской линии в момент завязывания семенных плодов кабачка. Результаты близкие к критическим значениям уровня гибридности для использования гибрида $F_{1}$ в производстве дала схема семеноводства с применением ручной кастрации материнской формы, в среднем за годы испытания значение составило - 95\% (табл. 3).

Ввиду возможного внутрилинейного опыления при завязывании третьего семенного плода, анализ разрабатываемой схемы с использованием обработки Этрелом был разделен на два отдельных варианта:

- выделение семян только их двух первых семенных плодов с растения;

- использование трех семенных плодов с растения. 
Таблица 3 - Уровень гибридности растений $\mathrm{F}_{1}$ в зависимости от типа опыления и схемы организации семеноводства (СЦ «Гавриш», г. Крымск, 2012-2014 годы).

\begin{tabular}{|c|c|c|c|c|c|c|c|c|}
\hline \multirow{5}{*}{\multicolumn{2}{|c|}{ Маркерные признаки }} & \multicolumn{7}{|c|}{ Процент растений с маркерными признаками в структуре популяций, \% } \\
\hline & & \multicolumn{2}{|c|}{ Родительские линии } & \multicolumn{5}{|c|}{ 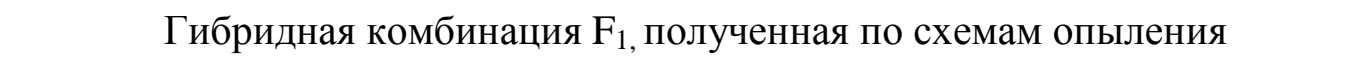 } \\
\hline & & \multirow{3}{*}{$\begin{array}{c}\mathrm{P}_{1} \\
\text { q форма }\end{array}$} & \multirow{3}{*}{$\begin{array}{c}\mathrm{P}_{2} \\
\delta \text { форма }\end{array}$} & \multirow{3}{*}{$\begin{array}{c}\text { Искусственное } \\
\text { с ручной } \\
\text { кастрацией и } \\
\text { изоляцией }+ \\
\text { цветков } \\
\text { (эталон) }\end{array}$} & \multicolumn{4}{|c|}{ Естественное (свободное), без изоляции ф цветков } \\
\hline & & & & & \multirow{2}{*}{$\begin{array}{c}\text { без } \\
\text { кастрации и } \\
\text { обработок } \\
\text { (контроль) }\end{array}$} & \multirow{2}{*}{$\begin{array}{c}\text { с ручной } \\
\text { кастрацией } \\
\hat{\jmath} \text { цветков }\end{array}$} & \multicolumn{2}{|c|}{$\begin{array}{l}\text { трехкратная обработка } \\
\text { Этрелом без кастрации }\end{array}$} \\
\hline & & & & & & & 1 вариант & 2 вариант \\
\hline \multirow{2}{*}{$\begin{array}{c}\text { Рассеченность } \\
\text { листовой } \\
\text { пластинки }\end{array}$} & сильная & 0 & 100 & 99,0 & 65,0 & 95,0 & 95,3 & 98,1 \\
\hline & средняя & 100 & 0 & 1 & 35,0 & 5,0 & 4,7 & 1,9 \\
\hline \multirow{3}{*}{$\begin{array}{c}\text { Выраженность } \\
\text { аэренхима }\end{array}$} & сильная & 0 & 100 & 0 & 0 & 0 & 0 & 0 \\
\hline & средняя & 0 & 0 & 99,0 & 65,0 & 95,0 & 95,3 & 98,1 \\
\hline & отсутствие & 100 & 0 & 1 & 35,0 & 5,0 & 4,7 & 1,9 \\
\hline \multicolumn{2}{|c|}{ Уровень гибридности, \% } & 0 & 0 & 99,0 & 65,0 & 95,0 & 95,3 & 98,1 \\
\hline
\end{tabular}


Положительные результаты показал вариант с применением Этрела, при использовании двух семенников с растения, образовавшихся до начала единичного цветения мужских цветков на материнских растениях, уровень гибридности в таком случае составляет - 98,1\%. При выделении семян из трех образовавшихся семенников на растении, уровень гибридности, соответственно был ниже и в среднем за годы исследований составил 95,3\%, что сравнимо с результативностью схемы гибридного семеноводства с применением ручной кастрации материнской формы, наиболее часто применяемой на производственных семеноводческих посевах в южных регионах РФ.

Завершающим исследованием являлась оценка уровня и структуры урожая гибридных растений кабачка, полученных при использовании различных схем организации гибридного семеноводства гибрида $\mathrm{F}_{1}$ 831/14 (таблица 4).

Таблица 4 - Структура урожая растений кабачка гибрида $\mathrm{F}_{1} 831 / 14$, в зависимости от типа опыления и схемы организации семеноводства (2013-2014 годы)

\begin{tabular}{|c|c|c|c|c|c|c|}
\hline \multirow{4}{*}{ Признаки } & \multicolumn{5}{|c|}{ Тип и схема опыления } & \multirow{4}{*}{$\mathrm{HCP}_{05}$} \\
\hline & \multirow{3}{*}{$\begin{array}{c}\text { Искусственное } \\
\text { с ручной } \\
\text { кастрацией и } \\
\text { изоляцией } q \\
\text { цветков } \\
\text { (эталон) }\end{array}$} & \multicolumn{4}{|c|}{ Естественное (свободное), без изоляции + цветков } & \\
\hline & & \multirow{2}{*}{$\begin{array}{c}\text { без } \\
\text { кастрации и } \\
\text { обработок } \\
\text { (контроль) }\end{array}$} & \multirow{2}{*}{$\begin{array}{c}\text { с ручной } \\
\text { кастрацией } \\
\widehat{\partial} \text { цветков }\end{array}$} & \multicolumn{2}{|c|}{$\begin{array}{c}\text { трехкратная } \\
\text { обработка Этрелом } \\
\text { без кастрации }\end{array}$} & \\
\hline & & & & 1 вариант & 2 вариант & \\
\hline $\begin{array}{c}\text { Число плодов на } \\
\text { растении, шт. }\end{array}$ & 11 & 8 & 11 & 11 & 12 & 0,9 \\
\hline Масса плода, кг & 0,6 & 0,7 & 0,6 & 0,6 & 0,6 & 0,1 \\
\hline Длина плода, см & 24,0 & 22,5 & 23,8 & 23,5 & 24,2 & 0,9 \\
\hline Диаметр плода, см & 6,8 & 7,6 & 6,9 & 7,0 & 6,8 & 0,4 \\
\hline $\begin{array}{c}\text { Продуктивность } \\
\text { общая, кг/раст. }\end{array}$ & 6,4 & 5,6 & 6,6 & 6,7 & 6,9 & 0,6 \\
\hline Товарность, \% & 93 & 87 & 91 & 91 & 93 & 3,2 \\
\hline $\begin{array}{c}\text { Урожайность } \\
\text { стандартной } \\
\text { продукции, т/га }\end{array}$ & 112,7 & 92,5 & 114,1 & 115,8 & 121,9 & 10,4 \\
\hline $\begin{array}{c}\text { Общая } \\
\text { урожайность, т/га }\end{array}$ & 121,2 & 106,4 & 125,4 & 127,3 & 131,1 & 7,3 \\
\hline
\end{tabular}


Во всех изученных вариантах получения семян гибрида кабачка, период от массовых всходов до 1-го сбора плода в технической зрелости, в среднем составил 47 суток. То есть способ организации и тип опыления, в данном случае, не повлиял на начало плодоношения гибрида кабачка $\mathrm{F}_{1}$ $831 / 14$.

$\mathrm{B}$ структуре урожая гибрида $\mathrm{F}_{1}$ важной составляющей является размер и масса плода, количество плодов на гибридном растении. Наименьшее число плодов -8 штук на растении, $\mathrm{F}_{1}$ зафиксировано в варианте семеноводства со свободным опылением, при получении семян $\mathrm{F}_{1}$ без кастрации и обработок. Несколько лучше результат у варианта с обработкой препаратом и использованием трех семенников (1 вариант семеноводства с Этрелом, гибридность 95,3\%) - около 10 плодов на растении, тогда как в остальных вариантах - более 11 плодов (табл. 4)

Аналогичная тенденция, была отмечена, соответственно, и с долей товарных плодов на растении, продуктивностью и урожаем стандартной продукции (табл. 4). Следует отметить, что в контрольном варианте с низким завязываем плодов на растении, отмечено некоторое увеличение массы плода (на 100 гр.) в технической зрелости, но в результате, все же более низкие показатели общей урожайности (на 14,8 - 24,7 кг/га).

Таким образом, в условиях Краснодарского края, схема семеноводства при естественном опылении с использованием Этрела и сбором трех семенных плодов (1 вариант), увеличивает выход семян гибрида $F_{1}$ кабачка дополнительно до 30 кг/га, а масса 1000 семян на 3\% выше, по сравнению со схемой, использующей ручную кастрацию.

\section{Выводы.}

1. Установлено, что лучшие результаты, с точки зрения количества и качества полученных семян гибрида $\mathrm{F}_{1}$, при использовании свободного опыления, имеют следующие методы организации гибридного семеноводства: 
- сдерживание цветения мужских цветков с помощью Этрела (трехкратное опрыскивание в фазы 3+4+5 настоящих листьев, доза 350 мг/л д.в.);

- регулярная ручная кастрация материнских растений.

2. Наиболее положительные результаты по уровню гибридности, структуре урожая, продуктивности гибридных растений F1 кабачка и его урожайностью, из всех изучаемых вариантов организации гибридного семеноводства, отмечены в варианте с естественным опылением, обработкой Этрелом и выделением семян только из двух первых семенных плодов с растения (вариант 2). В данном случае, обеспечивается высокая гибридность полученного потомства (>98\%), что соответствует современным требованиям сельхозпроизводителей к качеству «профессиональных» семян гибридов F1 кабачка. Семена с уровнем гибридности на уровне $95 \%$ +/- $2 \%$ вполне пригодны для мелких производителей и личных подсобных хозяйств.

\section{Список литературы:}

1. Буриев, Х.Ч. Справочная книга бахчевода, ред. Белик В.Ф. - М.: 1984.

2. Гусев, А..М. Изменчивость некоторых признаков в популяции овощных тыкв // Сб. тр. - М.: ТСХА. - 1989. - С. 17 - 19

3. Долженко М. В. Создание скороспелых гетерозисных гибридов F1 кабачка для Нечерноземной зоны России//автореферат диссертации, 2009.

4. Тараканов, Г.И., Гусев, А.М., Андриевская, С.А. Морфобиотипы Cucurbita pepo L. и их использование в селекции и производстве //Известия TCXA. - 1987.Вып.б.-С. 105-121.

5. Тараканов, Г.И., Теханович, Г.А., Елацкова, А.Г. Создание самоопыленных линий и изучение наследования некоторых генетических признаков у летних тыкв //Доклады МСХА. - 2001. - Вып. 273. - 4.2.

6. Чайкин К.О. Регулятор роста Этрел в гибридном семеноводстве кабачка // журнал Гавриш. 2015.-№ 3.-С.52-55.

7. Чайкин К.О. Химическая кастрация кабачка // журнал Картофель и Овощи. 2016. -№5.-С. 39-40.

8. Ecker J.R. The Ethylene Signal Transduction Pathway in Plants // Science. 1995. Vol. 268. P. 667-675. 
9. Lercari B., Testi R. The extent of cross-pollination in Cucurbita pepo L. with flowering habit modified by ethrel // Riv. Ortoflorofrutticolt. Ital. -1976. -Vol. 60. -№ 3. -P. 199-203.

10. Sams C., Krueger W. Ethephon alteration of flowering and fruit set pattern of summer squash // HortScience. -1977. -Vol. 12. -№ 2. -P. 162-164.

11. Suryanarayana, V.; Raju, B.N. Growth, flowering, sex expression and yield of pumpkin and ridgegourd as influenced by plant growth regulators // Andhra agr. J. -1985. Vol. 32. -№ 2. -P. 107-111.

12. Tesi, R, Lercari, B. Aspettitecnicidellaproduzione del semeibrido di zucca da zucchini (Cucurbitapepo L.) //SementiElette, 1977, т.23, №1, c.45 49.

\section{References}

1. Buriev, H.Ch. Spravochnaja kniga bahchevoda, red. Belik V.F. - M.: 1984.

2. Gusev, A..M. Izmenchivost' nekotoryh priznakov v populjacii ovoshhnyh tykv // Sb. tr. - M.: TSHA. - 1989. - S. 17 - 19

3. Dolzhenko M. V. Sozdanie skorospelyh geterozisnyh gibridov F1 kabachka dlja Nechernozemnoj zony Rossii//avtoreferat dissertacii, 2009.

4. Tarakanov, G.I., Gusev, A.M., Andrievskaja, S.A. Morfobiotipy Cucurbita rero L. i ih ispol'zovanie v selekcii i proizvodstve //Izvestija TSHA. - 1987.-Vyp.b.-S. 105-121.

5. Tarakanov, G.I., Tehanovich, G.A., Elackova, A.G. Sozdanie samoopylennyh linij i izuchenie nasledovanija nekotoryh geneticheskih priznakov u letnih tykv //Doklady MSHA. 2001. - Vyp. 273. - 4.2.

6. Chajkin K.O. Reguljator rosta Jetrel v gibridnom semenovodstve kabachka // zhurnal Gavrish. 2015.-№ 3.-S.52-55.

7. Chajkin K.O. Himicheskaja kastracija kabachka // zhurnal Kartofel' i Ovoshhi. 2016. -№5.-S. 39-40.

8. Ecker J.R. The Ethylene Signal Transduction Pathway in Plants // Science. 1995. Vol. 268. P. 667-675.

9. Lercari B., Testi R. The extent of cross-pollination in Cucurbita pepo L. with flowering habit modified by ethrel // Riv. Ortoflorofrutticolt. Ital. -1976. -Vol. 60. -№ 3. -P. 199-203.

10. Sams C., Krueger W. Ethephon alteration of flowering and fruit set pattern of summer squash // HortScience. -1977. -Vol. 12. -№ 2. -P. 162-164.

11. Suryanarayana, V.; Raju, B.N. Growth, flowering, sex expression and yield of pumpkin and ridgegourd as influenced by plant growth regulators // Andhra agr. J. -1985. Vol. 32. -№ 2. -P. 107-111.

12. Tesi, R, Lercari, B. Aspettitecnicidellaproduzione del semeibrido di zucca da zucchini (Cucurbitapepo L.) //SementiElette, 1977, t.23, №1, c.45 49. 